\title{
Morbilliform rash with deranged liver functions
}

\section{Cong Sun, Jim Muir}

\section{CASE}

A Caucasian woman aged 49 years presented with a three-day history of a widespread maculopapular erythematous eruption involving the torso, limbs and acral surfaces (Figure 1). There was marked peripheral oedema. The patient was also febrile to $38.2^{\circ} \mathrm{C}$ with tender lymphadenopathy involving the axillary and cervical lymph nodes. Blood pressure of $130 / 75 \mathrm{mmHg}$ and pulse of 85 beats per minute were stable.

The patient had no other systemic complaints. There was no history of mouth or genital ulcers. No potential sick contact was reported. She was otherwise medically well. Vaccination was up to date, and she was not immunosuppressed. No clinically significant travel history was reported. The patient used a levonorgestrel-releasing intrauterine device for contraception and over-thecounter herbal cream for mild psoriasis, both of which the patient had used for more than one year. Ibuprofen and naproxen were started two weeks ago for musculoskeletal pain.

\section{QUESTION 1}

What differential diagnosis should be considered in this presentation?

\section{QUESTION 2}

What additional clinical features on history and examination should be sought to differentiate the possible diagnosis?
QUESTION 3

What initial investigations should be performed in this case?

\section{ANSWER 1}

The aetiology of morbilliform eruptions is diverse. The list of differentials can range from morbilliform drug eruption, seroconversion reactions, viral exanthems and erythema multiforme to more serious severe cutaneous adverse reactions such as drug hypersensitivity syndrome (formerly known as drug reaction with eosinophilia and systemic symptoms [DRESS] syndrome) ${ }^{1,2}$

\section{ANSWER 2}

A thorough clinical history and examination should help to identify features that can be used to narrow the list of differential diagnosis (Table 1).

\section{ANSWER 3}

Investigations including full blood examination, electrolytes and liver

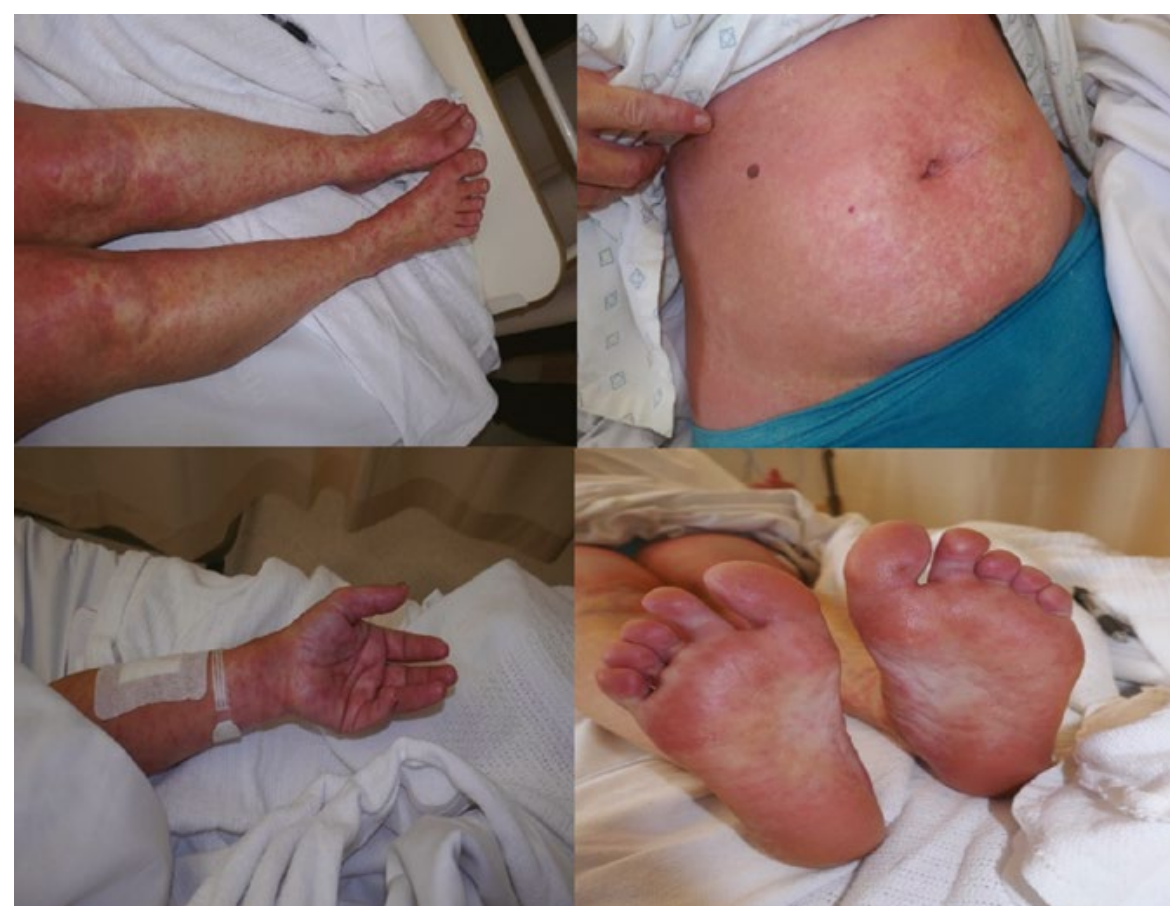

Figure 1. Maculopapular eruption on the limbs, trunk and acral surface 
function tests (LFTs) should be ordered. Viral serology is also helpful depending on risk factors and clinical findings. Punch biopsies should be performed for histopathology.

\section{CASE CONTINUED}

The patient was admitted to hospital. Physical examination was unremarkable. There was no palpable hepatosplenomegaly, and the patient was alert and orientated with no neurological deficits or photophobia.

Full blood examination showed a raised white cell count with a marked eosinophilia. LFTs were initially normal but showed elevated transaminase on the second day of admission. Viral and bacterial serologies - which included hepatitis $C$ virus, hepatitis B virus, human immunodeficiency virus, Epstein-Barr virus (EBV), herpes simplex virus and mycoplasma - were unremarkable. Three punch biopsies showed a spongiotic process with basal vacuolation, suggesting an interface dermatitis. A superficial perivascular infiltrate including eosinophils was also present.

\section{QUESTION 4}

What is the most likely diagnosis in this case?

\section{QUESTION 5}

What is the treatment of this condition?

\section{ANSWER 4}

The morbilliform eruption and oedema of affected skin, along with peripheral eosinophilia on full blood examination and deranged LFTs, strongly suggest the diagnosis of drug hypersensitivity syndrome. Nonsteroidal anti-inflammatory drugs (NSAIDs) are a

\section{Table 1. Relevant clinical features for differential diagnosis of morbilliform eruption with fever}

\begin{tabular}{ll}
\hline Differential diagnosis & Distinguishing clinical features \\
\hline Morbilliform drug eruption & - Absence of or very mild systemic symptoms \\
\hline Meningococcaemia & Known association with certain agents \\
& - Headache \\
& - Haemotophobia \\
& $\cdot$ Nuchal rigidity
\end{tabular}

Viral exanthem (eg rubeola, rubella, · Systemic manifestations (fever, lymphadenopathy, erythema infectiosum, roseola, human immunodeficiency virus, hepatitis $C$ virus, hepatitis $B$ virus, Epstein-Barr virus) hepatomegaly, splenomegaly, arthralgia, sore throat, etc)

- Sick contacts

\begin{tabular}{ll} 
& $\cdot$ Clinically significant travel history \\
\hline Erythema multiforme & Previous mouth or genital ulcers \\
$\cdot$ Respiratory symptoms (Mycoplasma pneumoniae) \\
$\cdot$ Possible mucosal involvement \\
$\cdot$ Targetoid lesions
\end{tabular}

Drug hypersensitivity syndrome

- Known association with certain medications

- Fever and lymphadenopathy

- Oedema of affected skin

- Haematological abnormalities (raised eosinophil and often leukocyte)

- Solid organ involvement (liver, kidney, heart, lung, gastrointestinal tract and central nervous system)

known trigger, along with anti-epileptic medications such as carbamazepine and antigout medication allopurinol. The histopathology is consistent with this diagnosis.

Drug hypersensitivity syndrome is a rare, potentially life-threatening adverse drug reaction with cutaneous manifestations and internal organ involvement. ${ }^{3,4}$

Although it was originally associated with phenytoin, many other medications have been implicated, including other anticonvulsants, sulfonamides, allopurinol, antivirals, antidepressants, NSAIDs and other miscellaneous medications. ${ }^{3,5}$ Polypharmacy can mean the causative agent cannot be reliably established.

Symptoms and signs usually start 3-6 weeks post commencement of the offending medication. The most common cutaneous manifestation is a morbilliform eruption, although urticarial, lichenoid, bullous and other types of rashes have been reported. The skin involvement can overlap with Stevens-Johnson syndrome, toxic epidermal necrolysis and acute generalised exanthematous pustulosis. The presence of lymphadenopathy, facial and acral oedema and fever are also characteristic of drug hypersensitivity syndrome.

The pathophysiology of drug sensitivity is complex and ultimately unclear. ${ }^{3,5,6} \mathrm{An}$ interplay between genetic predisposition to abnormal drug metabolism and reactivation of human herpesvirus $6, \mathrm{EBV}$ or cytomegalovirus is the most current viewpoint on this condition. $.3,5,6$

The work-up for drug hypersensitivity syndrome is extensive, given the various organs that can be involved (Table 2).

The histopathological features of drug hypersensitivity syndrome are often non-specific with no unique findings that would separate this condition from other spongiotic processes. ${ }^{3}$ Spongiosis is a common finding, along with perivascular infiltrates with eosinophils and interface dermatitis. ${ }^{3}$

As with all significant drug hypersensitivity reactions, it is important that the patient never be re-exposed to the offending agent or a 


\section{Table 2. Diagnostic work-up for drug hypersensitivity syndrome and its complications}

\begin{tabular}{ll}
\hline Investigations & Rationale \\
\hline $\begin{array}{l}\text { Full blood examination, } \\
\text { coagulation studies }\end{array}$ & $\begin{array}{l}\text { Eosinophilia is the most common manifestation in drug } \\
\text { hypersensitivity syndrome. Atypical lymphocytosis and } \\
\text { coagulopathy can also be present. }\end{array}$ \\
\hline Liver function tests & $\begin{array}{l}\text { The liver is the most commonly affected organ in drug } \\
\text { hypersensitivity syndrome, which can potentially lead to } \\
\text { fulminant hepatic failure. }\end{array}$ \\
\hline $\begin{array}{l}\text { Echocardiography, } \\
\text { electrocardiography, troponin }\end{array}$ & $\begin{array}{l}\text { Eosinophilic myocarditis is a rare and potentially fatal } \\
\text { complication of drug hypersensitivity syndrome and can } \\
\text { occur after a long delay. }\end{array}$ \\
\hline $\begin{array}{l}\text { Viral serology (eg human } \\
\text { herpesvirus 6, Epstein-Barr } \\
\text { virus, cytomegalovirus) }\end{array}$ & $\begin{array}{l}\text { Viral reactivation can be seen in drug hypersensitivity } \\
\text { syndrome as part of its pathophysiology. }\end{array}$ \\
\hline $\begin{array}{l}\text { Lung function test, chest } \\
\text { imaging }\end{array}$ & $\begin{array}{l}\text { The lung is the second most affected organ. Eosinophil } \\
\text { toxicity may cause interstitial pneumonitis. }\end{array}$ \\
\hline Thyroid function test & $\begin{array}{l}\text { Hypothyroidism can be a long-term sequela of drug } \\
\text { hypersensitivity, occurring long after the initial onset } \\
\text { of disease. }\end{array}$ \\
\hline
\end{tabular}

cross-reacting agent. For example, the three major anticonvulsants (ie phenytoin, carbamazepine and phenobarbitone) exhibit cross-reactivity. A 'medalert' bracelet should be worn carrying information about previous reactions. In regard to NSAIDs, the reaction tends to be selective; however, cross-reactivity can occur because of the similar chemical properties between different NSAIDs. ${ }^{7}$ Therefore, NSAIDs from all classes should be avoided, given the risk of another severe reaction to the medication.

The mortality of drug hypersensitivity syndrome is reported to be as high as $10 \% .^{3}$ Of those who survive, thyroid dysfunction and pancreatic insufficiency in the form of type 1 diabetes mellitus can occur, which warrant further follow-up.

\section{ANSWER 5}

The treatment is to stop the offending medication immediately as delay may be associated with poorer outcomes. ${ }^{5}$ Systemic corticosteroids are the most widely accepted therapy for drug hypersensitivity syndrome with significant systemic involvement. ${ }^{3,5}$ Other immunosuppressive agents such as cyclosporin, rituximab, cyclophosphamide and mycophenolate have also been reported as effective. A specialised burns unit or intensive care unit may be needed if cutaneous involvement progresses to erythroderma. ${ }^{3,5}$

\section{CASE CONTINUED}

The patient improved with a potent topical corticosteroid and oral antihistamine for symptomatic itch. No systemic corticosteroid was used, as her transaminase level stabilised, and no signs of new organ dysfunction developed. She was discharged after seven days of admission.

\section{Key points}

- Careful history and rigorous physical examination are warranted to triage the urgency of every presentation of fever and rash.

- A thorough medication history needs to be obtained, as medication-induced cutaneous eruptions are common.

- While most medication-related rashes take a benign course and can be managed in the community, some can lead to serious systemic manifestations and require urgent transfer to the hospital.

\section{Authors}

Cong Sun BSc, MD Resident Medical Officer, Princess Alexandra Hospital, Qld

Jim Muir MBBS, FACD, FACRRM (Hon), Consultant Dermatologist, Mater Hospital, Qld; Associate Professor, University of Queensland, Qld

Competing interests: None.

Funding: None.

Provenance and peer review: Not commissioned, externally peer reviewed.

Correspondence to:

tom.cong.sun@gmail.com

\section{References}

1. Gerson D, Sriganeshan V, Alexis JB. Cutaneous drug eruptions: A 5-year experience. J Am Acad Dermatol 2008;59(6):995-99. doi: 10.1016/j. jaad.2008.09.015

2. Korman AM, Alikhan A, Kaffenberger BH. Viral exanthems: An update on laboratory testing of the adult patient. J Am Acad Dermatol 2017;76(3):538-50. doi: 10.1016/j.jaad.2016.08.034

3. Cho YT, Yang CW, Chu CY. Drug Reaction with Eosinophilia and Systemic Symptoms (DRESS): An interplay among drugs, viruses, and immune system. Int J Mol Sci 2017:18(6):1243. doi: 10.3390/ ijms18061243.

4. Husain Z, Reddy BY, Schwartz RA. DRESS syndrome: Part I. Clinical perspectives. J Am Acad Dermatol 2013;68(5):693.e1-14; quiz 706-8. doi: 10.1016/j.jaad.2013.01.033.

5. Husain Z, Reddy BY, Schwartz RA. DRESS syndrome: Part II. Management and therapeutics. J Am Acad Dermatol 2013;68(5):709.e1-9; quiz 718-20. doi: 10.1016/j.jaad.2013.01.032.

6. Darlenski R, Kazandjieva J, Tsankov N. Systemic drug reactions with skin involvement: StevensJohnson syndrome, toxic epidermal necrolysis, and DRESS. Clin Dermatol 2015;33(5):538-41. doi: 10.1016/j.clindermatol.2015.05.005.

7. Lee SY, Nam YH, Koh YI, et al. Phenotypes of severe cutaneous adverse reactions caused by nonsteroidal anti-inflammatory drugs. Allergy Asthma Immunol Res 2019;11(2):212-21. doi: 10.4168/aair.2019.11.2.212 